\title{
Sticks and carrots for the design of international climate agreements with renegotiations
}

\author{
Hans-Peter Weikard • Rob Dellink
}

Published online: 17 September 2010

(C) The Author(s) 2010. This article is published with open access at Springerlink.com

\begin{abstract}
This paper examines renegotiations of international climate agreements for carbon abatement. We explore coalition stability under 'optimal transfers' that have been suggested to stabilise international environmental agreements (e.g. McGinty in Oxford Economic Papers 59, 45-62, 2007). Such transfer schemes need to be refined when agreements are renegotiated. We determine the requirements that transfers between signatories of an international climate agreement must satisfy in order to stabilise the sequence of agreements that performs best in terms of provision of the public good 'carbon abatement'. If these requirements are met, no country wants to change its membership status at any stage. In order to demonstrate the applicability of our result we use the STACO model, a 12-regions global model, to assess the impact of well-designed transfer rules on the stability of an international climate agreement. Although there are strong free-rider incentives, we find a stable grand coalition in the first commitment period in a game with one round of renegotiations if renegotations take place sufficiently early.
\end{abstract}

Keywords Stability of coalitions · International environmental agreements · Partition function approach $\cdot$ Sharing rules $\cdot$ Renegotiations $\cdot$ Climate agreements

\section{Introduction}

Efficient management of the global commons such as stability of climatic conditions and the conservation of biodiversity requires a grand coalition of the nation states responsible for environmental regulation and legislation. However, the grand coalition will generally not be stable as individual countries have an incentive to take a free-rider position in the provision of such global environmental goods. This paper examines the options to establish a stable international climate agreement (ICA) that comes as close as possible to the first best-but generally unstable_-grand coalition. The notion of stability we employ is crucial.

H.-P. Weikard $(\varangle) \cdot$ R. Dellink

Environmental Economics and Natural Resources Group, Department of Social Sciences, Wageningen University, Hollandseweg 1, $6706 \mathrm{KN}$ Wageningen, The Netherlands

e-mail: Hans-Peter.Weikard@wur.nl 
We use the concept of internal and external stability. A coalition is said to be stable if and only if no coalition member has an incentive to leave (internal stability) and no non-member has an incentive to join (external stability); cf. d'Aspremont et al. (1983). This notion of stability is applicable when the membership decision is taken only once (and for all). As we will relax this assumption and allow for renegotiations, we will introduce an appropriate refinement of the stability concept in Sect. 2 below.

There exists by now an extensive literature on the stability of international environmental agreements. Here we focus on games where a single agreement is proposed that can be signed or not. This class of games is usually called 'cartel games with open membership'. Different solution concepts have been employed to analyse this type of game. Hoel (1992) considers a 'constrained social optimum' where social net benefits from greenhouse gas (GHG) abatement are maximised subject to an individual rationality constraint that requires that coalition members gain compared to the non-cooperative equilibrium. Eyckmans (1999) examines coalition stability for uniform abatement efforts using a similar individual rationality constraint. Individual rationality is also a condition of the solution proposed by Chander and Tulkens (1995), the $\gamma$-core. Here it is implicitly assumed that a coalition would completely dissolve if a coalition member (or a subset of members) leaves. By contrast the notion of (internal and external) stability with single deviations implicitly assumes that the remaining coalition stays intact if a coalition member leaves. One might call this a pessimistic view where deviations occur whenever they are immediately profitable. In this paper we adopt this pessimistic —or cautious—view.

We explore the stability of international climate agreements. As it is conventional in the literature on international environmental agreements (e.g., Barrett 2005), we assume that countries can make binding agreements and, hence, we do not consider enforcement. Each player (countries or regions) chooses whether or not to sign the agreement and become a member of a unique coalition (the climate agreement). Then the coalition and the remaining singletons fix their abatement levels playing a Nash-Cournot game. As abatement is a pure public good, the equilibrium of the abatement game is generally inefficient. Only the coalition of all, the grand coalition, would overcome the inefficiency. The literature on cartel membership games has emphasised, however, that large coalitions, including the grand coalition, are only stable if gains from cooperation are small. If, however, gains from cooperation are large, stable coalitions are small and achieve relatively little (e.g. Barrett 1994; Finus and Rundshagen 2003). These results have been obtained for models with identical players and do not generalise when players differ (Weikard 2009). Our results in this paper are likewise in contrast to the earlier findings. We show that there are options to stabilise successful ICAs. There are three main drivers of our result.

First, we consider asymmetric countries. With asymmetric countries, in particular when countries differ in abatement cost, a coalition can exploit cheap abatement options if a low cost country joins the coalition. Low cost countries are attractive as coalition partners.

Second, we consider transfers between coalition members. Transfers or, more precisely, the sharing of the coalition payoff among members can be used to set incentives for low cost countries to join the coalition. In the debate on climate change policies a number of different sharing rules for international climate agreements have been suggested; see Rose et al. (1998). Only few studies have addressed the impacts of different sharing rules on the stability of international climate agreements. Bosello et al. (2003) consider sharing rules for abatement costs, Altamirano-Cabrera and Finus (2006) consider sharing rules for tradable emission permits and Weikard et al. (2006) consider sharing rules for the gains from cooperation. The differences are crucial. If sharing rules are applied to costs or permits, there is no guarantee that payoffs satisfy the individual rationality constraint. By contrast, 
if sharing is applied to the gains from cooperation, individual rationality is always satisfied as long as a coalition is at all profitable, i.e. it achieves at least the sum of what its members can achieve without cooperation. Recently a class of sharing rules has been proposed that divides the difference between the coalition payoff and the sum of the outside option payoffs of coalition members (Carraro et al. 2006; McGinty 2007; Weikard 2009; Fuentes-Albero and Rubio 2010). The outside option payoff is the payoff a player would receive when leaving the coalition. It is obvious that the internal stability condition can only be met when the coalition payoff exceeds the sum of the outside option payoffs. On the other hand, if the coalition payoff exceeds the sum of the outside option payoffs, then welldesigned transfers can guarantee internal stability. Here we introduce an adjusted "optimal sharing rule" designed for a setting with renegotiations.

Third, we allow for renegotiations of the agreement. Renegotiations improve the incentives to join a coalition. Players may be forced to cooperate at the first stage if there is a credible threat of punishment at the second stage. Moreover the second stage payoffs can be used to reward members of the first-stage agreement. There is a small but growing literature on renegotiations of international environmental agreements. Barrett $(1994,1999)$ considers an infinitely repeated game. Contrary to what a folk theorem would suggest, full participation cannot generally be achieved because the option to renegotiate limits the threats of punishment. Asheim et al. (2006) use a similar model but allow for regional agreements. The finding is that several regional agreements increase GHG abatement over one global agreement but, again, full participation is generally not achieved. Asheim and Holtsmark (2009) establish a "folk theorem" for a game with renegotiations and find full participation with efficient abatement levels only for discount rates sufficiently close to 1. Ulph (2004) and Rubio and Ulph (2007) have studied renegotiations of international environmental agreements with a stock pollutant. They find that as the gains from cooperation increase over time, participation declines. This reinforces Barrett's (1994) findings. In a recent paper De Zeeuw (2008) considers farsighted stability in a dynamic membership game and finds small as well as large stable coalitions. However, all these approaches are confined to symmetric countries and do not capture abatement cost differences and the impact of transfers to stabilise agreements. Our paper complements the literature in this respect.

To study the effects of optimally designed sharing rules in an applied setting and to illustrate their impacts we examine the stability of ICAs. We do this using the STACO model introduced by Finus et al. (2006) and refined by Nagashima et al. (2009). STACO is a global model comprising 12-regions for each of which abatement cost and benefit functions are defined. The numerical analysis in this paper extends the work of Weikard et al. (2006) who consider results from the STACO model and compare proportional sharing of gains from cooperation according to past emissions, regional income, population and other indicators. They find that an emission-based proportional sharing rule performs best in the sense that it stabilises a coalition that gives higher global net benefits and lower stocks of carbon pollution than any other of the examined rules. However, as only a limited set of rules was examined in that study, it remained an open question whether coalitions can be stabilised that perform even better. Our analysis in this paper shows that an optimal transfer rule gives significantly better results. If we do not consider renegotiations, we find that there exist stable coalitions of up to 6 out of 12 regions. The best performing stable coalition comprises 5 regions and achieves about $46 \%$ of the gains the Grand Coalition could achieve as compared to non-cooperation. With renegotiations, considering two commitment periods, we even find a stable grand coalition in the first commitment period of 10 or 20 years, followed by a 5 regions coalition for the second commitment period. These agreements achieve $59 \%$ of the potential gains over a century. 
The paper is organised as follows. The next section introduces optimal sharing rules for a multi-period setting. This section contains our main theoretical contribution: an extension of the internal-external stability concept and the characterisation of sharing rules that stabilise the best performing coalitions that can possibly be stable in a setting with renegotiations. Section 3 provides a brief overview of empirical specifications of the STACO model for our case of ICAs. Section 4 presents the results. Section 5 concludes.

\section{Optimal sharing in Pareto perfect coalitions}

We consider an open membership cartel formation game with renegotiations. That is, we consider several but finitely many periods (commitment periods) in each of which a single coalition or cartel (the ICA) can form. In each period $t=1, \ldots, T$ individual countries $i \in N$ decide to join or not to join the agreement. Payoffs that accrue in period $t$ depend on the coalition formed in that period $K^{t} \subseteq N$. Payoffs are determined from costs and benefits of equilibrium abatement of GHGs in an abatement game that is specified in the next section. Here it is sufficient to note that GHG abatement is a public good. It is well known for public goods games that the grand coalition $K=N$ is efficient, while any partial agreement with $K \subset N$ is not (e.g. Dasgupta 1982). In a public goods game a singleton coalition $K=\{i\}$ will not be effective and give the same payoffs as $K=\emptyset$. We will refer to both cases as 'All-Singletons'. To be more precise about payoffs, the abatement game in period $t$ invokes a partition function $V^{t}\left(K^{t}\right)$ that determines payoffs $V_{K}^{t}$ for the coalition and for each singleton player $V_{j}^{t}\left(K^{t}\right), j \notin K^{t}$ in period $t$. Before we can introduce our notion of stability (of a sequence of coalitions) we need to define individual payoffs for coalition members. We assume that some sharing rule $r$ applies that distributes the coalition payoff $V_{K}(K)$ among members. ${ }^{1}$ Thus we arrive at a per-member partition function, also commonly called 'valuation function'. For convenience we denote it by $V\left({ }^{r} K\right)$ and individual payoffs under coalition $K$ when sharing rule $r$ applies are denoted by $V_{i}\left({ }^{r} K\right)$. Of course, for every sharing rule $r$ we have $V_{K}(K)=\sum_{i \in K} V_{i}\left({ }^{r} K\right)$. We adopt the shorthand notation $K_{-i}$ for $K \backslash\{i\}$ with $i \in K$ and $K_{+j}$ for $K \cup\{j\}$ with $j \notin K$. Define the coalition surplus $S_{K} \equiv V_{K}(K)-\sum_{i \in K} V_{i}\left(K_{-i}\right)$. We call $V_{i}\left(K_{-i}\right) i$ 's outside option payoff or defection payoff. Note that it is, of course, independent of the sharing rule applied by coalition $K_{-i}$.

Now consider the final period $T$ and consider a class of sharing rules for coalition $K^{T}$ where each coalition member $i \in K^{T}$ receives at least its outside option payoff $V_{i}^{T}\left(K_{-i}^{T}\right)$ and a (non-negative) share $s_{i}^{T}$ of the surplus if this is feasible, i.e. if $S_{K^{T}} \geq 0$. Else, if $S_{K^{T}}<0$, losses will be shared. This class of sharing rules, referred to as 'optimal sharing', can be formally described as follows:

$$
\begin{aligned}
& V_{i}^{T}\left({ }^{r} K^{T}\right)=V_{i}^{T}\left(K_{-i}^{T}\right)+s_{i}^{T} \quad \text { for all } i \in K^{T}, \\
& \quad \text { with } \sum_{i \in K^{T}} s_{i}^{T}=S_{K^{T}} \quad \text { and }
\end{aligned}
$$

for all $i \in K^{T}, \quad s_{i}^{T} \geq 0 \quad$ if and only if $\quad S_{K^{T}} \geq 0 .^{2}$

Optimal sharing gives priority to setting incentives to join the agreement. Weikard (2009) shows that every coalition that is internally stable under some arbitrary sharing rule will also

\footnotetext{
${ }^{1}$ We skip the time-superscript where it is not essential.

${ }^{2}$ The latter requirement has been labelled 'Claim Rights Condition' by Weikard (2009).
} 
be internally stable under the family of sharing rules characterised by (1). The underlying standard notion of stability is as follows (d'Aspremont et al. 1983):

Definition 1 (i) A coalition $K$ is internally stable under sharing rule $r$ if and only if

$$
V_{i}\left({ }^{r} K\right) \geq V_{i}\left(K_{-i}\right) \quad \text { for all } i \in K
$$

(ii) A coalition $K$ is externally stable under sharing rule $r$ if and only if

$$
V_{j}(K)>V_{j}\left({ }^{r} K_{+j}\right) \quad \text { for all } j \in N \backslash K .^{3}
$$

(iii) A coalition $K$ is stable for given sharing rules if and only if it is internally and externally stable.

In a setting with renegotiations, the notion of stability of Definition 1 has to be refined. First, the object of stability is no longer a coalition under a sharing rule $r$, but rather a sequence of coalitions coupled with sharing rules $\left\langle r^{1} K^{1}, \ldots,{ }^{r^{T}} K^{T}\right\rangle$. We adopt the terminology that coalition ${ }^{r} K^{t}$ is generalised stable under sharing rule $r$ if no member wants to leave and no non-member wants to join. It is important to note that generalised stability of a coalition in a given period may depend on the coalitions formed and the sharing rules applied in other periods and therefore Definition 1 does not apply but needs refinement.

The coalition formation game we study is a finite sequential game and the equilibrium concept employed is Pareto perfect equilibrium introduced by Bernheim et al. (1987) and Benoît and Krishna (1993). This equilibrium concept is a refinement of Selten's $(1965,1975)$ subgame perfect equilibrium that rules out the play of a Pareto dominated subgame in an equilibrium path of play. ${ }^{4}$ Similar to the concept of subgame perfection, Pareto perfection requires that a Pareto perfect equilibrium is played in every subgame-including subgames that are off the equilibrium path of play. This implies that a punishment path of play, after a deviation has occurred, must also be Pareto perfect. If we have multiple Pareto perfect equilibria, we assume that players will coordinate on a punishment path playing the equilibrium that is worst for the deviating player.

Before formally defining Pareto perfect sequences of coalitions we need to introduce some further notation and a definition of generalised stability.

Denote by ${ }^{w} \tilde{K}_{i}^{T}$ the stable and Pareto undominated coalition with sharing rule $w$ that gives the worst payoff of all stable coalitions to player $i$ in period $T$, that is: $V_{i}^{T}\left({ }^{w} \tilde{K}_{i}^{T}\right) \leq$ $V_{i}^{T}\left({ }^{r} K^{T}\right)$ for all stable ${ }^{r} K^{T}$. This payoff serves as a threat for player $i$ in the preceding period. It is a credible threat because, as ${ }^{w} \tilde{K}_{i}^{T}$ is stable, no player has an incentive to deviate from this punishment strategy. Of course, $i$ may or may not be a member of $\tilde{K}_{i}^{T}$.

We can now recursively define generalised stability. A definition of Pareto perfect equilibrium follows.

\footnotetext{
${ }^{3}$ The tie-breaking rule is here that a player would join the coalition if she is indifferent between joining and staying out. Hence, by this definition, the empty set $\emptyset$ is not externally stable, and a trivial coalition is internally stable.

${ }^{4}$ Benoît and Krishna (1993) use the term "renegotiation proof" that is commonly used in the context of infinitely repeated games. They introduce the concept for two-player games. We extend the definition to $n$ players (Definition 3 below), but consider only single deviations. Hence we are not considering coalition proofness (Bernheim et al. 1987).
} 
Definition 2 (i) In the last period $T$ a coalition $K^{T}$ is generalised stable under sharing rule $r^{T}$ if and only if it is stable.

(ii) A sequence of coalitions $\left\langle r^{T-1} K^{T-1}, r^{T} K^{T}\right\rangle$ is generalised stable if and only if $r^{T} K^{T}$ is generalised stable, and for all $i \in K^{T-1}$

$$
V_{i}^{T-1}\left({ }^{r^{T-1}} K^{T-1}\right)+V_{i}^{T}\left({ }^{r^{T}} K^{T}\right) \geq V_{i}^{T-1}\left(K_{-i}^{T-1}\right)+V_{i}^{T}\left({ }^{w} \tilde{K}_{i}^{T}\right),
$$

and for all $j \in N \backslash K^{T-1}$

$$
V_{j}^{T-1}\left(K^{T-1}\right)+V_{j}^{T}\left(r^{T} K^{T}\right)>V_{j}^{T-1}\left({ }^{T-1} K_{+j}^{T-1}\right)+V_{j}^{T}\left({ }^{w} \tilde{K}_{j}^{T}\right) .
$$

(iii) For longer sequences conditions for generalised stability are established by working backwards from (2) and (3). Let $W_{i}^{t}$ be the payoff of the worst generally stable coalition sequence for player $i$ from time $t$ onward.

A sequence of coalitions of length $T-t+1$, i.e. $\left\langle r^{t} K^{t}, \ldots,{ }^{r^{T}} K^{T}\right\rangle$, is generalised stable if the subsequence of length $T-t$, i.e. $\left\langle r^{t+1} K^{t+1}, \ldots,{ }^{r T} K^{T}\right\rangle$, is generalised stable and if for all $i \in K^{t}$

$$
V_{i}^{t}\left(r^{t} K^{t}\right)+\sum_{\tau=t+1}^{T} V_{i}^{\tau}\left(r^{\tau} K^{\tau}\right) \geq V_{i}^{t}\left(K_{-i}^{t}\right)+W_{i}^{t+1},
$$

and for all $j \in N \backslash K^{t}$

$$
V_{j}^{t}\left(K^{t}\right)+\sum_{\tau=t+1}^{T} V_{j}^{\tau}\left(r^{\tau} K^{\tau}\right)>V_{j}^{t}\left(s^{t} K_{+j}^{t}\right)+W_{j}^{t+1} .
$$

Definition 3 (i) In the last period, coalition $K^{T}$ is Pareto perfect under sharing rule $r^{T}$ if and only if it is stable and Pareto undominated by any other stable coalition.

(ii) A sequence of coalitions $\left\langle r^{t} K^{t}, \ldots,{ }^{r T} K^{T}\right\rangle$ is Pareto perfect if and only if it is generalised stable and Pareto undominated by any other generalised stable sequence stretching from $t$ to $T$ and all its subsequences $\left\langle r^{t-1} K^{t-1}, \ldots,{ }^{T} K^{T}\right\rangle,\left\langle r^{t-2} K^{t-2}, \ldots,{ }^{r^{T}} K^{T}\right\rangle$, $\ldots,\left\langle r^{T} K^{T}\right\rangle$ are generalised stable and Pareto undominated.

In the remainder of the paper we confine the analysis to a two-period game, $T=2$. To extend the analysis to more periods is straightforward, based on Definitions 2 and 3, but tedious.

For $T=2, V_{i}^{2}\left({ }^{w} \tilde{K}_{i}^{2}\right)$ is the worst credible punishment that can be imposed on $i$ in period 2. Condition (2) requires of a Pareto perfect equilibrium $\left\langle r^{1} K^{1}, r^{2} K^{2}\right\rangle$ that the payoff of a period-1 coalition member (left hand side) is at least as large as the payoff from defecting from coalition $K^{1}$ (right hand side). It is a credible threat that ${ }^{w} \tilde{K}_{i}^{2}$ will be played as it is a Pareto perfect subgame equilibrium. Condition (3) requires that a singleton player in period 1 receives at least as much as when entering coalition $K^{1}$. Conditions (2) and (3) are generalisations of the notions of internal and external stability, respectively. In what follows we will sometimes say "coalition $K^{1}$ is generalised stable" in place of the correct but lengthy phrase "coalition $K^{1}$ is part of a generalised stable sequence of coalitions". This just means that no member of $K^{1}$ has an incentive to leave and no non-member has an incentive to join.

Using Definition 2 we can now establish a condition to determine whether for a given sequence of partition functions we can find valuations (or sharing rules) such that a sequence 
of coalitions is Pareto perfect. For simplicity we restrict the exposition to a time invariant partition function. Again, generalisations are straightforward but involve more tedious notation. ${ }^{5}$

First, we focus on generalised internal stability. From condition (2) we can see that a coalition $K^{1}$ can only be part of a generalised stable sequence if each member of $K^{1}$ receives at least its defection payoff

$$
D_{i}\left(K^{1}\right) \equiv V_{i}\left(K_{-i}^{1}\right)+V_{i}\left({ }^{w} \tilde{K}_{i}^{2}\right) .
$$

Therefore, a necessary condition for generalised internal stability of $K^{1}$ is that the sum of payoffs of the coalition members is at least as large as the sum of their defection payoffs:

$$
\sum_{i \in K^{1}}\left(V_{i}\left(r^{1} K^{1}\right)+V_{i}\left(r^{2} K^{2}\right)\right) \geq \sum_{i \in K^{1}} D_{i}\left(K^{1}\right)
$$

Generalised stability of $K^{1}$ depends upon defection payoffs of the members of $K^{1}$ and the sharing rule $r^{2}$ applied in period 2; the latter only if there is some $i \in K^{1} \cap K^{2}$. The defection payoff is further specified by the partition function that determines the payoffs of the singleton players and, hence, the period- 1 outside option payoff of $i \in K^{1}$, i.e. $V_{i}\left(K_{-i}^{1}\right)$ is independent of sharing. If player $i \in K^{1}$ defects, then its period-2 payoff is $V_{i}\left({ }^{w} \tilde{K}_{i}^{2}\right)$. If the player is singleton, i.e. $i \notin \tilde{K}_{i}^{2}$, the payoff is independent of the sharing rule $w$. If $i \in \tilde{K}_{i}^{2}$, then sharing rule $w$ applies and $i$ receives the worst possible payoff compatible with Pareto perfection of ${ }^{w} \tilde{K}_{i}^{2}$.

The next step in our argument is to determine how sharing in coalitions $K^{1}$ and $K^{2}$ can be arranged such that condition (4) is met in all cases where this is possible for a given partition function. To achieve this, the sharing rule $r^{2}$ applied to $K^{2}$ should distribute the coalition surplus $S_{K^{2}}$ entirely to 'permanent' members, i.e. members in $K^{1} \cap K^{2}$, leaving members of $K^{2}$ that are not members of $K^{1}$ with their outside option payoff. Intuitively this rewards coalition members of the first period and lowers their incentive for defection. Hence, by construction we have the following:

Proposition 1 (i) Consider a Pareto perfect period-2 coalition $K^{2}$. Suppose sharing in period 2 is arranged such that $\sum_{i \in K^{1} \cap K^{2}} V_{i}\left(r^{2} K^{2}\right)=S_{K^{2}}$. Then, if for such $K^{2}$ and $r^{2}$ condition (4) is not met, then $\left\langle r^{1} K^{1}, r^{2} K^{2}\right\rangle$ is not generalised internally stable and cannot be a Pareto perfect equilibrium for any sequence of sharing rules $r^{1}, r^{2}$.

(ii) Again, let $K^{2}$ be Pareto perfect. Suppose sharing in period 2 is arranged as stated under (i). Then, if for such $K^{2}$ and $r^{2}$ condition (4) is met for $K^{1}$, then there exists a sharing rule $r^{1 *}$ such that $\left\langle{ }^{1 *} K^{1}, r^{2} K^{2}\right\rangle$ is generalised internally stable.

Proof Part (i) follows from the construction of $S$. Part (ii) follows from the fact that in (4) the period-1 coalition payoff $\sum_{i \in K^{1}} V_{i}\left(r^{1} K^{1}\right)$ is independent of $r^{1}$ and from the fact that there is no restriction on $r^{1}$. Hence, as long as (4) holds, the period-1 coalition payoff $V_{K^{1}}$ can always be distributed in a way to meet the generalised internal stability condition (2) for each and every $i \in K^{1}$.

Proposition 1 allows us to identify all coalitions that can be generalised stable for a given partition function. We call a sharing rule that satisfies (2) for all $i \in K^{1}$ whenever (4) is

\footnotetext{
${ }^{5}$ Note that the partition function we use in Sects. 3 and 4 is not time-invariant.
} 
satisfied an "optimal sharing rule". Optimal sharing requires that $r^{1 *}$ is chosen such that $V_{i}\left(r^{1 *} K^{1}\right) \geq D_{i}\left(K^{1}\right)-V_{i}\left(r^{2} K^{2}\right)$ for all $i \in K^{1}$.

Next, we turn to external stability. The following proposition establishes that external stability, condition (3), is of little concern when an optimal sharing rule is applied.

Proposition 2 Consider a Pareto perfect period-2 equilibrium ${ }^{r^{2}} K^{2}$. If $K^{1}$ is generalised externally unstable under an optimal sharing rule $r^{1}$ (applied to $K_{+j}^{1}$ ) such that there exists $j \notin K^{1}$ with $V_{j}\left(K^{1}\right)+V_{j}\left(r^{2} K^{2}\right) \leq V_{j}\left(r^{1} K_{+j}^{1}\right)+V_{j}\left({ }^{w} \tilde{K}_{j}^{2}\right)$, meaning that $j$ prefers to enter coalition $K^{1}$ under sharing rule $r^{1}$, then the enlarged coalition ${ }^{r^{1}} K_{+j}^{1}$ will be generalised internally stable (and the equilibrium played in the continuation game is ${ }^{r^{2}} K^{2}$ ).

Proof By assumption $V_{j}\left(r^{1} K_{+j}^{1}\right)+V_{j}\left({ }^{w} \tilde{K}_{j}^{2}\right) \geq V_{j}\left(K^{1}\right)+V_{j}\left(r^{2} K^{2}\right)$. By definition $V_{j}\left({ }^{w} \tilde{K}_{j}^{2}\right) \leq V_{j}\left(r^{2} K^{2}\right)$. Hence, we have $V_{j}\left(r^{1} K_{+j}^{1}\right)+V_{j}\left(r^{2} K^{2}\right) \geq V_{j}\left(K^{1}\right)+V_{j}\left({ }^{w} \tilde{K}_{j}^{2}\right)$ which is what, according to (2), generalised internal stability of $K_{+j}^{1}$ requires. Furthermore, $r^{1}$ is an optimal sharing rule, if (2) applies to $j$, then it applies to all $i \in r^{1} K_{+j}^{1}$.

Propositions 1 and 2 allow us to identify the largest (or most successful) Pareto perfect coalitions in a coalition formation game for the provision public goods. To this we turn now. As a model with heterogeneous players does not readily yield general analytical characterisations of stable coalitions, we resort to numerical simulations.

\section{Numerical model and data}

This section and the next provide an application. We identify the best Pareto perfect equilibria in a greenhouse gas abatement game, that is, we identify a sequence of international climate agreements that is generalised stable and that achieves a higher global payoff than other generalised stable agreements. The stage game we consider is standard in this domain (e.g. Carraro and Siniscalco 1993; Barrett 1994; Botteon and Carraro 1997; Rubio and Ulph 2007). It consists of a membership game followed by an abatement game. We explore this game as a one-shot game (i.e. with one commitment period) and with one round of renegotiation (i.e. with two commitment periods). Formally, in the stage game we have a set of regions $N=\{1,2, \ldots, n\}$. At the beginning of commitment period $t(t=1,2)$ each player $i$ chooses from a strategy set $\sigma_{i}^{t} \in\{0,1\} ; \sigma_{i}^{t}=0$ means that $i$ is not joining the ICA in period $t ; \sigma_{i}^{t}=1$ means that $i$ joins the ICA in period $t$. As before, we denote by $K^{t} \subseteq N$ the set of coalition members (signatories) in commitment period $t$. Now consider a given coalition $K^{t}$. Chander and Tulkens (1995) call this a 'partial agreement'. In the period- $t$ abatement game members of $K^{t}$ act like a single player and maximise their joint payoff. They adopt GHG abatement paths which are jointly optimal responses to others' abatement paths. ${ }^{6}$ Other players, the singletons, maximise individual payoffs. They adopt abatement paths which are optimal responses to others' emissions. Generally we denote $i$ 's GHG abatement path in period $t$ by $\bar{q}_{i}^{t}$. The period- $t$ Nash equilibrium abatement strategy is denoted by $\bar{q}_{i}^{* t}\left(K^{t}\right)$. The abatement game described generates a partition function that gives

\footnotetext{
${ }^{6}$ McEvoy and Stranlund (2009) point out that this type of game does not address the compliance problem within the coalition, but typically assumes that the coalition can enforce members' assigned abatement targets costlessly.
} 
payoffs for the coalition and the singletons for every coalition that may form. ${ }^{7}$ Generally, each player receives benefits $b_{i}$ from total abatement $\bar{q}^{t}=\sum_{i \in N} \bar{q}_{i}^{t}$ and incurs costs $c_{i}$ for own abatement $\bar{q}_{i}^{t}$. A singleton player under coalition $K^{t}$ receives

$$
V_{i}^{t}\left(K^{t}\right)=b_{i}^{t}\left(\bar{q}^{* t}\left(K^{t}\right)\right)-c_{i}^{t}\left(\bar{q}_{i}^{* t}\left(K^{t}\right)\right), \quad \text { for all } i \in N \backslash K^{t} .
$$

The coalition payoff is given by

$$
V_{K^{t}}^{t}\left(K^{t}\right)=\sum_{i \in K^{t}}\left(b_{i}^{t}\left(\bar{q}^{* t}\left(K^{t}\right)\right)-c_{i}^{t}\left(\bar{q}_{i}^{* t}\left(K^{t}\right)\right)\right) .
$$

The partition function on which the stability analysis is based arises from the abatement game characterised by (5) and (6).

To further specify the model, we adopt the STACO-model introduced by Finus et al. (2006) and refined by Nagashima et al. (2009) and Weikard et al. (2010). Here, we focus on the main features of the model; in an Appendix we provide details on the specification of the benefit and abatement cost functions. We consider twelve world regions: USA (USA), Japan (JPN), European Union-15 (EU15), other OECD countries (OOE), Eastern European countries (EET), former Soviet Union (FSU), energy exporting countries (EEX), China (CHN), India (IND), dynamic Asian economies (DAE), Brazil (BRA) and rest of the world (ROW). We account for benefits from abatement to infinity, but adopt a finite planning horizon of 100 years, ranging from 2011 to 2110, for determining abatement paths. This reflects the fact that fossil fuels, the main source of GHG emissions, are depletable. In this setting the intertemporal aspects of climate change are well reflected. Benefits from abatement are avoided damages which, in turn, depend on stock of $\mathrm{CO}_{2}$; each region receives a share of global benefits. Marginal benefits can be assumed to be constant. Marginal abatement costs are assumed to be a quadratic function of the region's own abatement level. The assumption of linear benefits implies that regions have dominant strategies; the optimal response functions do neither depend on the actions of other players, nor on the stock of greenhouse gases. We calibrate the model as far as possible (regional emission and GDP paths, regional abatement costs) on the MIT-EPPA model (Babiker et al. 2001 and Ellerman and Decaux 1998), but as this model does not contain a damage cost module, we have to rely on other sources (mainly Nordhaus and Boyer 2001 and Tol 1997) for calibrating the benefits from abatement; see Nagashima et al. (2009) and Dellink et al. (2009) for more details.

\section{Results and discussion}

This section presents the results of coalition formation for the STACO game with one commitment period (4.1) and two commitment periods (4.2).

\subsection{Optimal sharing in the one-shot game}

In the one-shot game, coalition members commit to abatement and transfer paths for the full planning period of 100 years. We find 108 out of $2^{12}-12=4084$ coalitions are stable and

\footnotetext{
${ }^{7}$ One qualification is needed. The partial agreement abatement game generates a partition function only if it has a unique solution. This condition is satisfied in the empirical setting of the STACO model, see Weikard et al. (2010).
} 
Table 1 Best performing stable coalitions-one-shot game

\begin{tabular}{lcc}
\hline Coalition members & $\begin{array}{l}\text { NPV of payoff } \\
{[\text { Billion US\$] }}\end{array}$ & $\begin{array}{l}\text { Concentrations } \\
2110[\mathrm{ppm}]\end{array}$ \\
\hline All-Singletons $^{\text {a }}$ & 5238 & 680 \\
Grand Coalition $^{\text {a }}$ & 15211 & 612 \\
USA, EET, CHN, IND, DAE $^{-}$ & 9830 & 659 \\
EU15, EET, EEX, CHN, IND & 9810 & 659 \\
EU15, OOE, EET, CHN, IND & 9701 & 659 \\
EU15, EET, CHN, IND, DAE & 9697 & 659 \\
USA, EET, EEX, CHN, DAE, BRA & 9613 & 660 \\
EU15, OOE, EET, EEX, CHN, BRA & 9486 & 660 \\
USA, CHN, IND, DAE, BRA & 9484 & 660 \\
EU15, EET, EEX, CHN, DAE, BRA & 9484 & 660 \\
USA, OOE, EET, EEX, CHN & 9469 & 660 \\
EU15, EEX, CHN, IND, BRA & 9455 & 660 \\
\hline
\end{tabular}

${ }^{a}$ All-Singletons and Grand Coalition are not stable

Pareto undominated. In Table 1 we present net present values (NPVs) and resulting $\mathrm{CO}_{2}$ concentrations for the benchmark cases (All-Singletons and Grand Coalition) and for the stable coalitions that perform best in terms of global NPV of payoffs.

With asymmetric players, as in our setting, global payoff does not just depend on the number of players in the coalition but also on their characteristics. For instance, coalitions where China is a member will generally implement higher abatement levels than coalitions where China is not involved. As China's marginal abatement costs are low compared to other regions, the efficient division of abatement efforts will involve a substantial contribution of China. In fact, China appears as member in all ten best-performing coalitions. Of course, China's involvement in a coalition requires sufficient availability of transfers-else China would prefer to take a free-rider position. We find China in 50 out of 108 stable coalitions.

Table 2 provides more detailed information for the non-cooperative ("All-Singletons") case, which is unstable, and for the best performing stable coalition. We report abatement levels and payoffs for individual regions. As a reference, abatement in 2011 and discounted payoffs are reported. Also reported is the Incentive to change membership. This indicator measures the change in payoff a region obtains when it unilaterally switches from being a member to being singleton or vice versa. When the incentive to change membership is positive for any region, it would prefer to change and thus the coalition is unstable. The best performing coalition consists of the USA, Central and Eastern European Countries in Transition (EET), China, India and the Dynamic Asian Economies (DAE). All regions are better off under partial cooperation than in the non-cooperative situation, showing that the gains from cooperation are substantial.

The member with the highest marginal benefits from abatement in the best performing equilibrium is the USA; thus, the transfer scheme involves a payment from the USA to the other regions, as shown in Table 2. China's low marginal abatement costs induce a huge abatement effort by China and the associated costs are largely funded by the transfer scheme.

Japan and EU15 are the main beneficiaries from this coalition and take a free-rider position. They do not increase their abatement efforts, but benefit much from the fact that coalition members abate more than under All-Singletons. This reflects the public good char- 
Table 2 Key results for selected coalitions-one-shot game ${ }^{\mathrm{a}}$

\begin{tabular}{|c|c|c|c|c|c|c|}
\hline & \multicolumn{2}{|c|}{ All-Singletons } & \multicolumn{4}{|c|}{ Coalition of USA, EET, CHN, IND, DAE } \\
\hline & $\begin{array}{l}\text { Abatement } \\
\text { in } 2011 \\
\text { [\% of } \mathrm{BaU} \\
\text { emissions] }\end{array}$ & $\begin{array}{l}\text { NPV of } \\
\text { payoff } \\
{[\text { Billion US\$] }}\end{array}$ & $\begin{array}{l}\text { Abatement } \\
\text { in } 2011 \\
{[\% \text { of } \mathrm{BaU}} \\
\text { emissions] }\end{array}$ & $\begin{array}{l}\text { NPV of } \\
\text { payoff } \\
\text { [Billion US\$] }\end{array}$ & $\begin{array}{l}\text { NPV of } \\
\text { transfer } \\
\text { [Billion US\$] }\end{array}$ & $\begin{array}{l}\text { Incentive to change } \\
\text { membership } \\
\text { (NPV) } \\
\text { [Billion US\$] }\end{array}$ \\
\hline USA & 9.9 & 1117 & 13.2 & 1603 & -663 & -9 \\
\hline JPN & 2.5 & 943 & 2.5 & 1933 & 0 & -207 \\
\hline EU15 & 7.6 & 1240 & 7.6 & 2595 & 0 & -274 \\
\hline OOE & 5.6 & 188 & 5.6 & 386 & 0 & -19 \\
\hline EET & 4.4 & 71 & 28.7 & 138 & 64 & -1 \\
\hline FSU & 6.7 & 362 & 6.7 & 749 & 0 & -59 \\
\hline EEX & 1.9 & 164 & 1.9 & 336 & 0 & -15 \\
\hline $\mathrm{CHN}$ & 14.8 & 298 & 50.1 & 415 & 452 & -2 \\
\hline IND & 10.5 & 268 & 37.8 & 485 & 83 & -3 \\
\hline DAE & 1.9 & 136 & 18.1 & 261 & 64 & -1 \\
\hline BRA & 0.1 & 84 & 0.1 & 172 & 0 & -4 \\
\hline ROW & 6.3 & 365 & 6.3 & 755 & 0 & -60 \\
\hline Global & 8.0 & 5238 & 16.9 & 9830 & 0 & -654 \\
\hline
\end{tabular}

${ }^{a}$ Bold numbers indicate membership

acteristic of abatement. Thus, their incentive to join the coalition (to change membership) is large and negative.

\subsection{Optimal sharing in the renegotiation game}

\subsubsection{Renegotiations after 50 years}

As discussed in the introduction, renegotiations may influence the outcome as players can change their membership decision. Introducing a round of renegotiations after 50 years may induce larger coalitions at the first stage, as non-cooperative behaviour may be punished by playing a worse equilibrium at the second stage.

Table 3 shows that there are multiple equilibria at the second stage. This opens possibilities for punishment and brings about a huge number of equilibria at the first stage. Table 3 reports NPVs of payoffs for the 10 best performing Pareto perfect coalition sequences (PPCs). The table offers a number of interesting observations.

First, although the second stage of the game has a shorter time horizon than the one-shot game, the best performing equilibrium coalitions are largely the same. The best performing generalised stable coalitions at the first stage are, however, more ambitious. While in the one-shot game $46 \%$ of the potential gain from cooperation can be reaped, the two-stage game can close the gap between All-Singletons and the Grand Coalition by 57\%. The combination of renegotiations and a scheme of optimal transfers makes a significant difference. In comparison, a two-stage game with an exogenous transfer rule can only reap $25 \%$ of the potential gain (cf. Weikard et al. 2010).

Secondly, the three best performing PPCs (and many other PPCs) contain one of the three high damage regions (USA, Japan or EU15) at the first stage but a different high damage 
Table 3 Best performing stable coalitions—renegotiations after 50 years

\begin{tabular}{lllll}
\hline Coalition members & \multicolumn{3}{c}{ NPV of payoff [billion US\$] } \\
\hline $1^{\text {st }}$ stage & $2^{\text {nd }}$ stage & $1^{\text {st }}$ st. & $2^{\text {nd }}$ st. & Total \\
\hline JPN, OOE, EET, FSU, CHN, IND, DAE, ROW & USA, EET, CHN, IND, DAE & 6528 & 4409 & 10937 \\
JPN, OOE, EET, FSU, CHN, IND, DAE, ROW & EU15, EET, EEX, CHN, IND & 6528 & 4402 & 10930 \\
EU15, EET, FSU, CHN, IND, DAE, ROW & USA, EET, CHN, IND, DAE & 6511 & 4409 & 10920 \\
EU15, EET, FSU, CHN, IND, DAE, ROW & EU15, EET, EEX, CHN, IND & 6511 & 4402 & 10912 \\
JPN, OOE, EET, FSU, CHN, IND, DAE, ROW & EU15, EET, CHN, IND, DAE & 6528 & 4352 & 10880 \\
USA, OOE, EET, EEX, CHN, IND, ROW & USA, EET, CHN, IND, DAE & 6469 & 4409 & 10878 \\
JPN, OOE, EET, FSU, CHN, IND, DAE, ROW & EU15, OOE, EET, CHN, IND & 6528 & 4346 & 10874 \\
USA, EET, EEX, CHN, IND, DAE, ROW & USA, EET, CHN, IND, DAE & 6463 & 4409 & 10872 \\
USA, OOE, EET, EEX, CHN, IND, ROW & EU15, EET, EEX, CHN, IND & 6469 & 4402 & 10871 \\
USA, OOE, EET, FSU, EEX, CHN, IND & USA, EET, CHN, IND, DAE & 6458 & 4409 & 10868 \\
\hline
\end{tabular}

region at the second stage. Notice that these regions have strong free-rider incentives and therefore face a severe punishment at the second stage if they defect at the first stage. Hence, they can be "persuaded" to join the coalition at the first stage. Free-riding at both stages has become more difficult due to the possibility of punishment.

Thirdly, as argued in Sect. 2, permanent members can share the entire surplus in the last period leaving temporary members with their outside option payoff. This reward gives an additional incentive to second stage coalition members to join already at the first stage: EET, China and India are present in all 10 best performing PPCs at both stages. For the regions with high marginal benefits, this reward is not always sufficient to compensate for the large free-rider incentives and the high transfers that they have to pay when joining a coalition. Thus, we find that especially the OECD regions are just temporary members of a climate coalition.

Table 4 gives the main regional results for the best performing sequence of coalitions. As there are no punishments at the second (last) stage by definition, the equilibria at this stage are not only self-enforcing, but also individually beneficial: all players are worse off when they leave the coalition, though the differences are sometimes small. This can be seen from the negative incentives to change membership at the second stage. Note also that the USA, as the only non-permanent member at the second stage, only receives its outside option payoff (the permanent members divide the surplus), and thus its incentive to change membership at this stage is exactly zero.

The punishment options are clearly visible in the incentives to change membership for the coalition members at the first stage. All temporary coalition members would be better off if they could free-ride and leave the coalition. Their decision is, however, not based on a simple comparison of net benefits at the first stage, but on their net benefits over the full century. The possibility to punish free-riders at the second stage induces the cooperation of regions that would rather prefer to free-ride at the first stage. The permanent members can also be forced into cooperation using the "stick" of punishment, but they also benefit from the "carrot" of dividing the surplus that is generated at both stages among themselves.

As in the one-shot game, the non-participating OECD regions, in this case USA at the first stage and EU15 at both stages, benefit strongly from the coalition that is formed, as their climate damages are substantially reduced, while their own abatement costs are moderate.

The pattern of transfers across coalition members is in line with expectations: the regions with large marginal benefits gain from the high abatement levels in the regions with low 
Table 4 Key results for the coalition of $\{$ JPN, OOE, EET, FSU, CHN, IND, DAE, ROW $\}$ and $\{$ USA, EET, CHN, IND, DAE $\}$ for the first and second stage, respectively-renegotiations after 50 years ${ }^{\mathrm{a}}$

\begin{tabular}{|c|c|c|c|c|c|c|c|c|}
\hline & \multicolumn{2}{|l|}{ Abatement } & \multicolumn{2}{|c|}{ NPV of payoff } & \multicolumn{2}{|c|}{ NPV of transfer } & \multirow{2}{*}{\multicolumn{2}{|c|}{$\begin{array}{l}\text { Incentive to change } \\
\text { membership (NPV) }\end{array}$}} \\
\hline & \multirow{2}{*}{$\begin{array}{l}2011 \\
{[\% \text { of } \mathrm{BaU}} \\
\text { emissions] }\end{array}$} & \multirow{2}{*}{$\begin{array}{l}2061 \\
{[\% \text { of } \mathrm{BaU}} \\
\text { emissions] }\end{array}$} & \multirow[b]{2}{*}{$\begin{array}{l}1^{\text {st }} \text { com- } \\
\text { mitment } \\
\text { period } \\
\text { [Billion } \\
\text { US\$] }\end{array}$} & \multirow[b]{2}{*}{$\begin{array}{l}2^{\text {nd }} \text { com- } \\
\text { mitment } \\
\text { period } \\
\text { [Billion } \\
\text { US\$] }\end{array}$} & \multirow[b]{2}{*}{$\begin{array}{l}1^{\text {st }} \text { com- } \\
\text { mitment } \\
\text { period } \\
\text { [Billion } \\
\text { US\$] }\end{array}$} & \multirow[b]{2}{*}{$\begin{array}{l}2^{\text {nd }} \text { com- } \\
\text { mitment } \\
\text { period } \\
\text { [Billion } \\
\text { US\$] }\end{array}$} & & \\
\hline & & & & & & & $\begin{array}{l}1^{\text {st }} \text { com- } \\
\text { mitment } \\
\text { period } \\
\text { [Billion } \\
\text { US\$] }\end{array}$ & $\begin{array}{l}2^{\text {nd }} \text { com- } \\
\text { mitment } \\
\text { period } \\
\text { [Billion } \\
\text { US\$] }\end{array}$ \\
\hline USA & 9.9 & 8.7 & 1701 & 722 & 0 & -295 & -266.2 & 0.0 \\
\hline JPN & 6.5 & 2.6 & 657 & 865 & -668 & 0 & 436.1 & -90.7 \\
\hline EU15 & 7.6 & 5.7 & 1817 & 1161 & 0 & 0 & -273.3 & -120.2 \\
\hline OOE & 21.0 & 2.9 & 164 & 173 & -47 & 0 & 87.2 & -8.4 \\
\hline EET & 33.0 & 17.3 & 122 & 62 & 80 & 28 & -25.3 & -0.7 \\
\hline FSU & 18.4 & 5.0 & 291 & 336 & -126 & 0 & 170.6 & -25.9 \\
\hline EEX & 1.9 & 1.7 & 235 & 150 & 0 & 0 & -31.0 & -6.7 \\
\hline $\mathrm{CHN}$ & 59.0 & 26.8 & 447 & 188 & 583 & 200 & -149.9 & -2.3 \\
\hline IND & 44.2 & 16.9 & 450 & 219 & 194 & 38 & -107.4 & -2.6 \\
\hline DAE & 21.8 & 13.0 & 233 & 117 & 108 & 29 & -50.4 & -1.4 \\
\hline BRA & 0.1 & 0.1 & 120 & 77 & 0 & 0 & -18.4 & -1.6 \\
\hline ROW & 20.8 & 4.4 & 293 & 338 & -125 & 0 & 171.9 & -26.2 \\
\hline Global & 21.5 & 11.0 & 6528 & 4409 & 0 & 0 & & \\
\hline
\end{tabular}

${ }^{a}$ Bold numbers indicate membership

marginal abatement costs and co-finance abatement there. Furthermore, permanent members appropriate the entire surplus generated by the coalition, and thus transfers tend to go from temporary members to permanent members. Coalitional maximisation requires that marginal abatement costs are equal across coalition members and equal to the sum of marginal benefits of all coalition members. For singletons, marginal abatement costs equal their own marginal benefits.

\subsubsection{Optimal renegotiation time}

Earlier renegotiations may induce even larger coalitions at the first stage. A longer second stage increases the threats that can be imposed on regions at the first stage. The generalised stable coalitions of the first stage are generally more ambitious than the stable coalitions of the second stage (see also Weikard et al. 2010). A shortening of the first stage may not increase the performance of the resulting equilibria over the century. It may, however, boost cooperation at the first stage. While earlier renegotiations thus increase threats that help to stabilise larger coalitions, later renegotiations maintain the benefits of a larger first stage coalition for longer. As these two mechanisms work in opposite directions, there is an optimal renegotiation moment where the additional benefit from high abatement levels balances with prolonged abatement at the first stage.

We find that the moment of renegotiation only affects the equilibria that emerge in the first commitment period, as shown in Table 5. Stability in the second commitment period is robust with respect to the length of the period. In the first commitment period, however, the possibilities for credible punishment are crucial for the stabilisation of more ambitious 
Table 5 Key results for different moments of renegotiations

\begin{tabular}{|c|c|c|c|c|}
\hline \multirow{2}{*}{$\begin{array}{l}\text { Renegotiations } \\
\text { after ... years }\end{array}$} & \multicolumn{4}{|l|}{ Best performing PPC } \\
\hline & Members $1^{\text {st }}$ commitment period & $\begin{array}{l}\text { Members } 2^{\text {nd }} \\
\text { commitment } \\
\text { period }\end{array}$ & $\begin{array}{l}\text { NPV of } \\
\text { payoff } \\
\text { [billion US\$] }\end{array}$ & $\begin{array}{l}\text { Concentra- } \\
\text { tions } 2110 \\
{[\mathrm{ppm}]}\end{array}$ \\
\hline 10 & $\begin{array}{l}\text { USA, JPN, EU15, OOE, EET, FSU, } \\
\text { EEX, CHN, IND, DAE, BRA, ROW }\end{array}$ & $\begin{array}{l}\text { USA, EET, CHN, } \\
\text { IND, DAE }\end{array}$ & 10451 & 657 \\
\hline 20 & $\begin{array}{l}\text { USA, JPN, EU15, OOE, EET, FSU, } \\
\text { EEX, CHN, IND, DAE, BRA, ROW }\end{array}$ & $\begin{array}{l}\text { USA, EET, CHN, } \\
\text { IND, DAE }\end{array}$ & 11073 & 654 \\
\hline 30 & $\begin{array}{l}\text { USA, JPN, OOE, EET, FSU, EEX, } \\
\text { CHN, IND, DAE, BRA, ROW }\end{array}$ & $\begin{array}{l}\text { USA, EET, CHN, } \\
\text { IND, DAE }\end{array}$ & 11431 & 654 \\
\hline 40 & $\begin{array}{l}\text { USA, EET, FSU, EEX, CHN, IND, } \\
\text { DAE, BRA, ROW }\end{array}$ & $\begin{array}{l}\text { USA, EET, CHN, } \\
\text { IND, DAE }\end{array}$ & 11238 & 655 \\
\hline 50 & $\begin{array}{l}\text { JPN, OOE, EET, FSU, CHN, IND, } \\
\text { DAE, ROW }\end{array}$ & $\begin{array}{l}\text { USA, EET, CHN, } \\
\text { IND, DAE }\end{array}$ & 10937 & 655 \\
\hline 60 & USA, EET, EEX, CHN, IND, ROW & $\begin{array}{l}\text { USA, EET, CHN, } \\
\text { IND, DAE }\end{array}$ & 10647 & 656 \\
\hline 70 & USA, OOE, EET, EEX, CHN, IND & $\begin{array}{l}\text { USA, EET, CHN, } \\
\text { IND, DAE }\end{array}$ & 10397 & 657 \\
\hline 80 & EU15, EET, CHN, IND, ROW & $\begin{array}{l}\text { USA, EET, CHN, } \\
\text { IND, DAE }\end{array}$ & 10096 & 657 \\
\hline 90 & USA, EET, EEX, CHN, IND & $\begin{array}{l}\text { USA, EET, CHN, } \\
\text { IND, DAE }\end{array}$ & 9938 & 658 \\
\hline
\end{tabular}

coalitions: the later the renegotiations, the weaker the threats and hence the less ambitious the best performing PPCs.

When the renegotiation moment is sufficiently early, the Grand Coalition can be stabilised in the first commitment period. In fact, most large coalitions are generalised stable when renegotiations are held after 10 or 20 years, including the 11-player coalitions where Brazil or Japan free-ride. The intuition behind this result is that these two regions have very steep marginal abatement cost curves. Their participation in the coalition requires that, even though they are temporary members and will not get more than their outside-option payoff, a substantial share of the surplus generated by the coalition would go to these regions to compensate their high abatement costs. But their participation would hardly benefit other regions, as their abatement levels would remain relatively small.

Because the larger stable coalitions exist for a shorter first commitment period, they do not contribute very much to the payoff over the entire planning horizon. Although the Grand Coalition is stabilised when renegotiations are held after 20 years, only 59\% of the total potential gains of cooperation are reaped $(100 \%$ at the first stage, $46 \%$ at the second stage). The best moment to renegotiate, in terms of maximising payoff of the best performing PPC, is after 30 years: this balances a sufficiently long first commitment period to enable prolonged strong abatement policies with sufficiently high threats to ensure stability of this ambitious coalition in the first commitment period. In this case, $62 \%$ of the potential gains of cooperation are reaped. By contrast, for renegotiations after 90 years only $47 \%$ of the potential gains can be reaped-hardly better than what can be achieved in the one-shot game.

The regional results of the overall best performing PPCs are presented Table 6. The most striking result is that all signatories that are not remaining in the coalition at the second stage would have an incentive to leave the coalition at the first stage if they would not be 
Table 6 Key results for the coalition of $\{$ USA, JPN, OOE, EET, FSU, EEX, CHN, IND, DAE, BRA, ROW and $\{$ USA, EET, CHN, IND, DAE $\}$ at the first and second stage, respectively-renegotiations after 30 years

\begin{tabular}{|c|c|c|c|c|c|c|c|c|}
\hline & \multicolumn{2}{|l|}{ Abatement } & \multicolumn{2}{|c|}{ NPV of payoff } & \multicolumn{2}{|c|}{ NPV of transfer } & \multicolumn{2}{|c|}{$\begin{array}{l}\text { Incentive to change } \\
\text { membership (NPV) }\end{array}$} \\
\hline & $\begin{array}{l}2011 \\
{[\% \text { of } \mathrm{BaU}} \\
\text { emissions] }\end{array}$ & $\begin{array}{l}2061 \\
{[\% \text { of } \mathrm{BaU}} \\
\text { emissions] }\end{array}$ & $\begin{array}{l}1^{\text {st }} \text { com- } \\
\text { mitment } \\
\text { period } \\
\text { [Billion } \\
\text { US\$] }\end{array}$ & $\begin{array}{l}2^{\text {nd }} \text { com- } \\
\text { mitment } \\
\text { period } \\
\text { [Billion } \\
\text { US\$] }\end{array}$ & $\begin{array}{l}1^{\text {st }} \text { com- } \\
\text { mitment } \\
\text { period } \\
\text { [Billion } \\
\text { US\$] }\end{array}$ & $\begin{array}{l}2^{\text {nd }} \text { com- } \\
\text { mitment } \\
\text { period } \\
\text { [Billion } \\
\text { US\$] }\end{array}$ & $\begin{array}{l}\text { members } \\
1^{\text {st }} \text { com- } \\
\text { mitment } \\
\text { period } \\
\text { [Billion } \\
\text { US\$] }\end{array}$ & $\begin{array}{l}\mathrm{p}(\mathrm{NPV}) \\
2^{\text {nd }} \text { com- } \\
\text { mitment } \\
\text { period } \\
\text { [Billion } \\
\text { US\$] }\end{array}$ \\
\hline USA & 19.7 & 10.6 & 1570 & 1071 & 323 & -434 & -425.9 & -5.9 \\
\hline JPN & 9.4 & 2.8 & 353 & 1282 & -779 & 0 & 650.2 & -135.5 \\
\hline EU15 & 7.6 & 6.5 & 1577 & 1721 & 0 & 0 & -291.5 & -179.3 \\
\hline OOE & 26.1 & 3.8 & 90 & 256 & -73 & 0 & 130.0 & -12.5 \\
\hline EET & 41.4 & 20.7 & 76 & 92 & 60 & 41 & 8.0 & -0.5 \\
\hline FSU & 22.9 & 5.3 & 153 & 497 & -170 & 0 & 254.4 & -38.7 \\
\hline EEX & 23.9 & 1.8 & 76 & 223 & -22 & 0 & 113.1 & -10.0 \\
\hline $\mathrm{CHN}$ & 76.5 & 30.6 & 359 & 277 & 688 & 296 & -94.0 & -1.5 \\
\hline IND & 56.6 & 21.3 & 303 & 322 & 128 & 54 & -1.9 & -1.8 \\
\hline DAE & 29.2 & 15.1 & 148 & 173 & 65 & 42 & 11.2 & -1.0 \\
\hline BRA & 5.1 & 0.1 & 44 & 114 & -52 & 0 & 57.7 & -2.4 \\
\hline ROW & 26.5 & 4.9 & 154 & 501 & -168 & 0 & 256.3 & -39.2 \\
\hline Global & 30.4 & 12.8 & 4902 & 6529 & 0 & 0 & & \\
\hline
\end{tabular}

Bold numbers indicate membership

punished at the second stage. For some regions, abatement levels are very large at the first stage, especially for China and India. In the absence of transfers, China would lose more than 300 billion US\$ on their own abatement efforts. ${ }^{8}$ Clearly, they need to be compensated for this with substantial transfers. Japan is willing to provide these transfers, as its benefits from global abatement are very high. The USA has a prominent position in this equilibrium: they benefit from the large credible threats that enforce an ambitious coalition at the first stage, and they benefit from the division of surplus among permanent members. In absolute terms (NPV of payoff), they are the main beneficiary of the agreement, together with the European Union (EU15), who benefit from free-riding.

Figure 1 shows the time profile of annual global abatement percentages for the best performing PPC of the different specifications and, for comparison, for the All-Singletons case. ${ }^{9}$ In line with the observations made in Table 5, more effective coalitions are established in the first commitment period, and after renegotiations abatement levels fall back to the level of the 5-player coalition of the second commitment period. The figure clearly shows the trade-off between level of ambition and duration of the first commitment period. It

\footnotetext{
${ }^{8}$ This can be seen in the table as the payoff minus the transfers received.

${ }^{9}$ In all cases, abatement percentages are falling for the first 7 decades, but increase slightly thereafter. The falling percentages are caused by increases in baseline emission levels that have a bigger impact than the increased abatement levels induced by technological progress. The slowdown of emission growth in the later decades causes abatement percentages to slightly increase towards the end of the century (cf. Nagashima et al. 2009).
} 


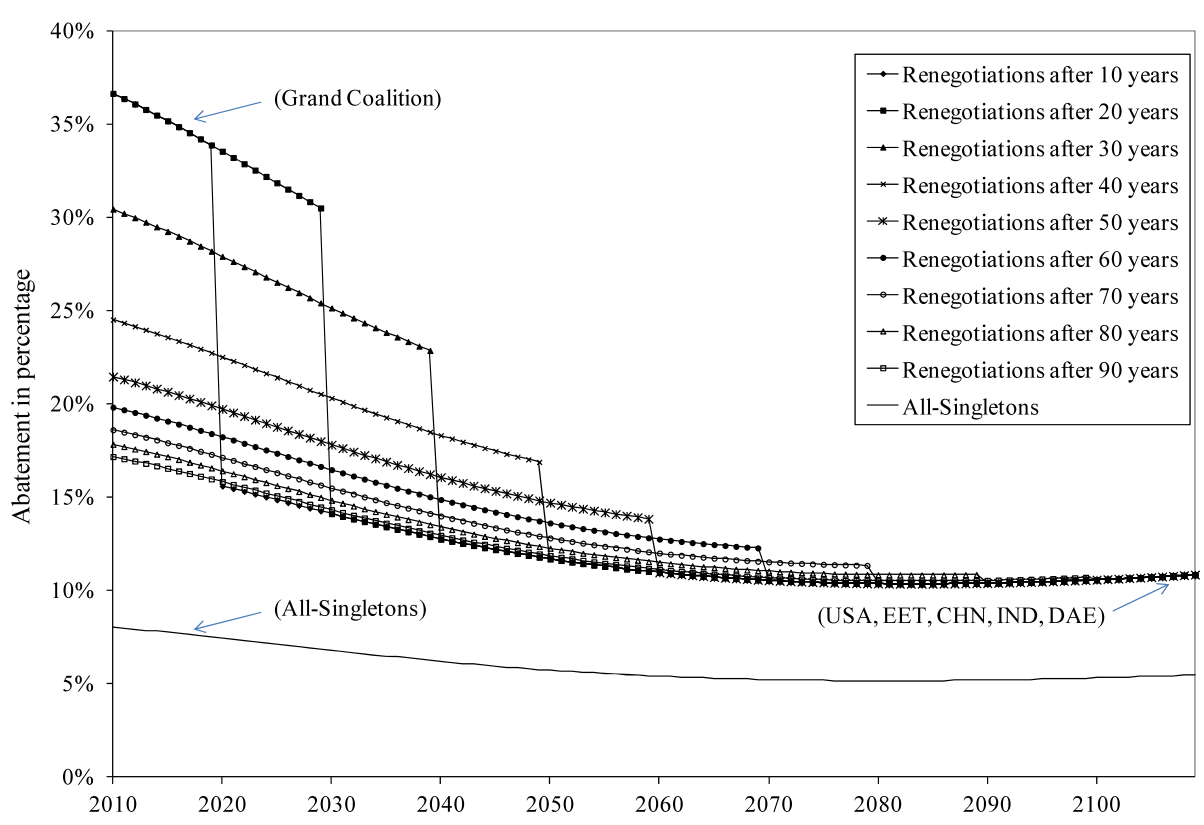

Fig. 1 Global emission reductions in percentages for the All-Singletons case and the best performing PPCs in the different simulations

also shows that an optimal transfer scheme is able to induce substantially higher abatement levels throughout the century than when no agreement is signed.

\section{Conclusion}

Although our analysis employs a cautious equilibrium concept-we assume that a region would defect from a coalition if its free-rider payoff is larger than its payoff in the coalition-, we find equilibria with a large degree of cooperation. Our findings are in contrast to many other studies that find only small stable coalitions consisting of no more than two or three players; see e.g. Barrett's (1994) theoretical analysis and the analysis of Finus et al. (2006) using the STACO model. There are three main drivers of our results. First, a well-designed transfer scheme is a useful tool to stabilise larger coalitions, as in our setting players differ in marginal benefits and marginal costs. Second, the transfer scheme that we suggest is specifically designed to increase the incentives to join the coalition. With such optimal transfers internal stability can be achieved for the largest possible set of coalitions. Third, we introduce renegotiations. Multiple equilibria at the second stage can be used as a threat to force potential free-riders into cooperation at the first stage. Together, these sticks and carrots provide substantial incentives for regions to join international climate agreements.

Acknowledgements We wish to thank two anonymous reviewers for careful checking the manuscript and helpful suggestions. We are indebted to our collaborators in the STACO project and particularly acknowledge fruitful discussions with Eligius Hendrix. 
Open Access This article is distributed under the terms of the Creative Commons Attribution Noncommercial License which permits any noncommercial use, distribution, and reproduction in any medium, provided the original author(s) and source are credited.

\section{Appendix}

A full description of the STACO model without renegotiations and details on the calibration procedure are provided by Dellink et al. The model with renegotiations is discussed in more detail in Weikard et al. (2010). Here, we provide a brief summary of the elements that are used to calculate the benefits and costs of abatement. All parameters are introduced in Table 7.

\section{A.1 Benefits and costs of abatement in STACO-2.2}

Development of the global stock of $\mathrm{CO}_{2}$ as a function of abatement

$$
M_{t}\left(M_{t-1}, q_{1}, \ldots, q_{t}\right)=\bar{M}+(1-\delta) \cdot\left(M_{t-1}\left(q_{1}, \ldots, q_{t-1}\right)-\bar{M}\right)+\omega \cdot \sum_{i=1}^{n}\left(\bar{e}_{i t}-q_{i t}\right)
$$

Global damages as a function of stock of $\mathrm{CO}_{2}$

$$
d_{t}\left(M_{t}\right)=\left[\gamma_{1}+\gamma_{2} \cdot\left(\frac{M_{t}\left(q_{1}, \ldots, q_{t}\right)}{\bar{M}}\right)\right] \cdot\left(\gamma_{D} \cdot y_{t}\right)
$$

\begin{tabular}{|c|c|c|c|c|}
\hline \multicolumn{2}{|c|}{ SymbolDescription } & \multirow{2}{*}{$\begin{array}{l}\text { Value } \\
590\end{array}$} & \multirow{2}{*}{$\frac{\text { Unit }}{\mathrm{GtC}}$} & \multirow{2}{*}{$\begin{array}{l}\text { Source } \\
\text { Nordhaus (1994) }\end{array}$} \\
\hline $\bar{M}$ & Pre-industrial level of $\mathrm{CO}_{2}$ stock & & & \\
\hline$M_{t_{0}}$ & $\begin{array}{l}\text { Stock of } \mathrm{CO}_{2} \text { in } 2010 \text {, starting point } \\
\text { for calculations }\end{array}$ & 835 & $\mathrm{GtC}$ & Nordhaus (1994) \\
\hline $\bar{e}_{i t}$ & Business As Usual (BAU) emissions & & $\mathrm{GtC}$ & Paltsev et al. (2005) \\
\hline$\delta$ & $\begin{array}{l}\text { Natural annual removal rate of } \mathrm{CO}_{2} \\
\text { stock }\end{array}$ & \multicolumn{2}{|c|}{$0.00866-$} & Nordhaus (1994) \\
\hline$\omega$ & $\begin{array}{l}\text { Airborne fraction of emissions } \\
\text { remaining in the atmosphere }\end{array}$ & 0.64 & - & Nordhaus (1994) \\
\hline$r$ & Discount rate & 0.02 & - & Assumption \\
\hline$\theta_{i}$ & Share of region $i$ in global benefits & \multicolumn{2}{|c|}{ see Table 8 , column 4} & $\begin{array}{l}\text { Own calculation based on } \\
\text { Fankhauser (1995) and Tol (1997) }\end{array}$ \\
\hline$\alpha_{i}$ & Abatement cost parameter of region $i$ & \multicolumn{2}{|c|}{ see Table 8 , column 2} & $\begin{array}{l}\text { Own calculation based on Ellerman } \\
\text { and Decaux (1998) }\end{array}$ \\
\hline$\beta_{i}$ & Abatement cost parameter of region $i$ & \multicolumn{2}{|c|}{ see Table 8 , column 3} & $\begin{array}{l}\text { Own calculation based on Ellerman } \\
\text { and Decaux (1998) }\end{array}$ \\
\hline$\varsigma$ & Technological progress parameter & 0.005 & - & Assumption \\
\hline$\gamma_{D}$ & $\begin{array}{l}\text { Scale parameter of damage and } \\
\text { benefit function }\end{array}$ & 0.027 & - & Tol (1997) \\
\hline
\end{tabular}

Table 7 STACO model parameters 
Table 8 Regional parameters

\begin{tabular}{llll}
\hline Regions & $\begin{array}{l}\text { Parameter of } \\
\text { abatement cost } \\
\alpha_{i}\end{array}$ & $\begin{array}{l}\text { Parameter of } \\
\text { abatement cost } \\
\beta_{i}\end{array}$ & $\begin{array}{l}\text { Parameter of } \\
\text { benefit function } \\
\theta_{i}\end{array}$ \\
\hline USA & 0.0005 & 0.0398 & 0.226 \\
JPN & 0.0155 & 1.8160 & 0.173 \\
EU15 & 0.0024 & 0.1503 & 0.236 \\
OOE & 0.0083 & 0 & 0.035 \\
EET & 0.0079 & 0.0486 & 0.013 \\
FSU & 0.0023 & 0.0042 & 0.067 \\
EEX & 0.0032 & 0.3029 & 0.030 \\
CHN & 0.00007 & 0.0239 & 0.062 \\
IND & 0.0015 & 0.0787 & 0.050 \\
DAE & 0.0047 & 0.3774 & 0.025 \\
BRA & 0.5612 & 8.4974 & 0.015 \\
ROW & 0.0021 & 0.0805 & 0.068
\end{tabular}

Global and regional benefits

$$
\begin{gathered}
b_{t}\left(q_{1}, \ldots, q_{t}\right)=d_{t}\left(M_{t}(\mathbf{0})\right)-d_{t}\left(M_{t}\left(q_{1}, \ldots, q_{t}\right)\right) \\
b_{i t}\left(q_{1}, \ldots, q_{t}\right)=\theta_{i} \cdot b_{t}\left(q_{1}, \ldots, q_{t}\right)
\end{gathered}
$$

Abatement costs

$$
c_{i t}\left(q_{i t}\right)=\frac{1}{3} \cdot \alpha_{i} \cdot(1-\varsigma)^{t} \cdot q_{i t}^{3}+\frac{1}{2} \cdot \beta_{i} \cdot(1-\varsigma)^{t} \cdot q_{i t}^{2}
$$

Discounted benefits

$$
B_{i}(\mathbf{q}) \equiv \sum_{t=1}^{\infty}\left\{(1+r)^{-t} \cdot b_{i t}(\mathbf{q})\right\}
$$

Discounted abatement costs

$$
C_{i}\left(\mathbf{q}_{\mathbf{i}}\right) \equiv \sum_{t=1}^{\infty}\left\{(1+r)^{-t} \cdot c_{i t}\left(q_{i t}\right)\right\}
$$

\section{References}

Altamirano-Cabrera, J.-C., \& Finus, M. (2006). Permit trading and stability of international climate agreements. Journal of Applied Economics, 9, 19-47.

Asheim, G. B., \& Holtsmark, B. (2009). Renegotiation-proof climate agreements with full participation: Conditions for Pareto efficiency. Environmental and Resource Economics, 43, 519-533.

Asheim, G. B., Bretteville Froyn, C., Hovi, J., \& Menz, F. C. (2006). Regional versus global cooperation for climate control. Journal of Environmental Economics and Management, 51, 93-109. 
Babiker, M. H., Reilly, J. M., Mayer, M., Eckaus, R. S., Wing, I. S., \& Hyman, R. C. (2001). The MIT emissions prediction and policy analysis (EPPA) model: revisions, sensitivities and comparison of results. MIT joint program on the science and policy of global change. Report No. 71, Cambridge.

Barrett, S. (1994). Self-enforcing international environmental agreements. Oxford Economic Papers, 46, 878894.

Barrett, S. (1999). A theory of full international cooperation. Journal of Theoretical Politics, 11(4), 519-541.

Barrett, S. (2005). Environment and statecraft-the strategy of environmental treaty-making. Oxford: Oxford University Press.

Benoît, J.-P., \& Krishna, V. (1993). Renegotiation in finitely repeated games. Econometrica, 61, 303-323.

Bernheim, B. D., Peleg, B., \& Whinston, M. D. (1987). Coalition-proof Nash equilibria I. Concepts. Journal of Economic Theory, 42, 1-12.

Bosello, F., Buchner, B., \& Carraro, C. (2003). Equity, development and climate change control. Journal of the European Economic Association, 1(2-3), 600-611.

Botteon, M., \& Carraro, C. (1997). Burden-sharing and coalition stability in environmental negotiations with asymmetric countries. In C. Carraro (Ed.), Environmental policy, international agreements and international trade (pp. 26-55). Cheltenham: Edward Elgar.

Carraro, C., \& Siniscalco, D. (1993). Strategies for international protection of the environment. Journal of Public Economics, 52, 309-328.

Carraro, C., Eyckmans, J., \& Finus, M. (2006). Optimal transfers and participation decisions in international environmental agreements. Review of International Organizations, 1, 379-396.

Chander, P., \& Tulkens, H. (1995). A core-theoretic solution for the design of cooperative agreements on transfrontier pollution. International Tax and Public Finance, 2, 279-293.

Dasgupta, P. (1982). The control of resources. Oxford: Blackwell.

d'Aspremont, C., Jaquemin, A., Gabszewicz, J. J., \& Weymark, J. A. (1983). On the stability of collusive price leadership. Canadian Journal of Economics, 16(1), 17-25.

Dellink, R., Nagashima, M., Van Ierland, E., Hendrix, E., Saiz, E., \& Weikard, H.-P. (2009). STACO technical document 2: Model description and calibration of STACO-2.1. www.enr.wur.nl/uk/staco. Wageningen: Wageningen University.

De Zeeuw, A. (2008). Dynamic effects on the stability of international environmental agreements. Journal of Environmental Economics and Management, 55, 163-174.

Ellerman, A. D., \& Decaux, A. (1998). Analysis of post-Kyoto $\mathrm{CO}_{2}$ emissions trading using marginal abatement curves (MIT Report \#40). Cambridge: MIT.

Eyckmans, J. (1999). Strategy proof uniform effort sharing schemes for transfrontier pollution problems. Environmental and Resource Economics, 14(2), 165-189.

Fankhauser, S. (1995). Valuing climate change: The economics of the greenhouse. London: Earthscan.

Finus, M., \& Rundshagen, B. (2003). Endogenous coalition formation in global pollution control: a partition function approach. In C. Carraro (Ed.), The endogenous formation of economic coalitions (pp. 199243). Cheltenham: Edward Elgar.

Finus, M., Van Ierland, E., \& Dellink, R. (2006). Stability of climate coalitions in a cartel formation game. Economics of Governance, 7, 271-291.

Fuentes-Albero, C., \& Rubio, S. J. (2010). Can the international environmental cooperation be bought? European Journal of Operational Research, 202(1), 255-264.

Hoel, M. (1992). International environmental conventions: the case of uniform reductions of emissions. Environmental and Resource Economics, 2, 141-159.

McEvoy, D. M., \& Stranlund, J. K. (2009). Self-enforcing international environmental agreements with costly monitoring for compliance. Environmental and Resource Economics, 42, 491-508.

McGinty, M. (2007). International environmental agreements among asymmetric nations. Oxford Economic Papers, 59, 45-62.

Nagashima, M., Dellink, R., van Ierland, E. C., \& Weikard, H.-P. (2009). Stability of international climate coalitions-A comparison of transfer schemes. Ecological Economics, 68, 1476-1487.

Nordhaus, W. D. (1994). Managing the global commons: The economics of climate change. Cambridge: MIT Press.

Nordhaus, W. D., \& Boyer, J. (2001). Warming the world: Economic models of global warming. Cambridge: MIT Press.

Paltsev, S., Reilly, J. M., Jacoby, H. D., Eckaus, R. S., McFarland, J., Sarofim, M., Asadoorian, M., \& Babiker, M. (2005). The MIT emissions prediction and policy analysis (EPPA) model: version 4. MIT joint program on the science and policy of global change. Report 125. Cambridge: MIT.

Rose, A., Stevens, B., Edmonds, J., \& Wise, M. (1998). International equity and differentiation in global warming policy. An application to tradeable emissions permits. Environmental and Resource Economics, 12, 25-51. 
Rubio, S. J., \& Ulph, A. (2007). An infinite horizon model of dynamic membership of international environmental agreements. Journal of Environmental Economics and Management, 54, 296-310.

Selten, R. (1965). Spieltheoretische Behandlung eines Oligopolmodels mit Nachfrageträgheit. Zeitschrift für die gesamte Staatswissenschaft, 121, 301-324 \& 667-689.

Selten, R. (1975). Reexamination of the perfectness concept for equilibrium points in extensive games. International Journal of Game Theory, 4, 25-55.

Tol, R. S. J. (1997). A decision-analytic treatise of the enhanced greenhouse effect. PhD-thesis, Amsterdam: Vrije Universiteit.

Ulph, A. (2004). Stable international environmental agreements with a stock pollutant, uncertainty and learning. Journal of Risk and Uncertainty, 29(1), 53-73.

Weikard, H.-P. (2009). Cartel stability under an optimal sharing rule. The Manchester School, 77(5), 599616.

Weikard, H.-P., Finus, M., \& Altamirano-Cabrera, J. C. (2006). The impact of surplus sharing on the stability of international climate agreements. Oxford Economic Papers, 58, 209-232.

Weikard, H.-P., Dellink, R., \& Van Ierland, E. (2010). Renegotiations in the greenhouse. Environmental and Resource Economics, 45, 573-596. 